\title{
Deprivation of Liberty Safeguards in England: implementation costs
}

\author{
Ajit Shah, Mark Pennington, Chris Heginbotham and Cam Donaldson
}

\section{Background}

The Deprivation of Liberty Safeguards (DoLS), introduced into the Mental Capacity Act 2005, were fully implemented on 1 April 2009 in England and Wales. The government estimated 20000 assessments for DoLS at a cost of $£ 600$ per assessment.

\section{Aims}

To estimate the costs likely to be incurred with the implementation of DoLS in England.

\section{Method}

The cost of conducting a single DoLS assessment was estimated using resource-utilisation data ascertained from 37 professionals, secretarial staff and independent mental capacity advocates involved with DoLS assessments in six diverse local DoLS offices.

\section{Results}

The estimated average cost of a single DoLS assessment was £1277.

\section{Conclusions}

The estimated average cost of a single DoLS assessment was significantly higher than the $£ 600$ estimated by the government. However, the allocated budget, based on 20000 estimated DoLS assessments in the first year of its implementation, is likely to be adequate because a significantly lower number of assessments (only 5200) were conducted in the first 9 months after its implementation.

\section{Declaration of interest}

C.H. was the Chief Executive of the Mental Health Act Commission until 31 March 2008.
A man with autism (HL), with no ability to communicate consent or dissent to hospital admission, was admitted informally to the mental health unit of the Bournewood Community and Mental Health NHS Trust following agitated behaviour at a day centre. The European Court of Human Rights, in 2004, found that the circumstances of HL's care and treatment during a period in which he was not formally detained under the Mental Health Act 1983 constituted infringement, in the form of deprivation of liberty, of his rights under Articles 5 (1) and 5 (4) of the European Convention on Human Rights. ${ }^{1}$ Article 5 (1) was breached because the manner in which HL was deprived of liberty was not in accordance with 'a procedure prescribed by law.' Article 5 (4) was breached because HL was not able to apply to a court to decide whether the deprivation of liberty was lawful. There was general agreement in the specialist literature that steps should be taken to comply with this ruling and considerable debate in legal circles about developing appropriate legislation, including strengthening the guardianship order. Following protracted discussion, the government amended the Mental Capacity Act 2005, by amending clauses in the Mental Health Act 2007, with the introduction of the Deprivation of Liberty Safeguards (DoLS) for individuals whose care or treatment involves deprivation of liberty within the framework of Article 5 of the European Convention on Human Rights, but who were not detained under the Mental Health Act. This represented a clear shift from the traditional 'doctor knows best' culture in the management of compliant, but incapable, individuals, where doctors exercised complete and effective control. It is widely accepted that this legislation is a somewhat complex afterthought to the Mental Capacity Act $2005 .^{2}$

The DoLS applies to both hospitals and care homes in England and Wales and was implemented on 1 April 2009. Multidisciplinary professionals and managers working in mental health and general hospital settings and in care homes need to be familiar with this new legislation and the six different assessments required for DoLS. These six assessments are as follows. (a) Age assessment - this confirms that the individual is 18 years or older as authorisation cannot be given to those under the age of 18 .

(b) Mental health assessment - this establishes the presence or absence of a mental disorder as defined in the Mental Health Act 1983. This assessor is required to be equivalent to a Section 12-approved doctor under the Mental Health Act.

(c) Mental capacity assessement - this establishes whether the individual lacks the capacity to consent to the arrangements proposed for their care.

(d) Best interest assessment - this establishes that if deprivation of liberty is occuring or is going to occur it is in the best interest of the individual to be deprived of liberty, deprivation of liberty is necessary to prevent harm to the individual, and the deprivation of liberty is proportionate to the likelihood of the individual suffering harm and the seriousness of the harm. This assessor is required to be equivalent of an approved mental health professional as defined in the Mental Health Act.

(e) Eligibility assessment - this establishes the individuals's status or potential status under the Mental Health Act with the aim of confirming whether the individual should be subject to the Mental Health Act or the DoLS under the Mental Capacity Act 2005.

(f) No refusal assessment - this establishes whether authorisation of deprivation of liberty would conflict with other authorites (for example power of attorney) for decision-making for that individual.

The mental health and best interests assessments have required to be conducted by two different professionals. Thus, a minimum of two assessors are required to complete the six DoLS assessments.

The Regulatory Impact Assessment for DoLS estimated that 20000 individuals (16000 in care homes and 4000 in hospitals) in England will require assessments in the first year of the 
implementation of DoLS. ${ }^{3}$ The government has provided additional funding of $£ 10$ million for local authority and $£ 2.2$ million for the National Health Service (NHS) for the implementation of DoLS. ${ }^{4}$ Thus, the cost of a single DoLS

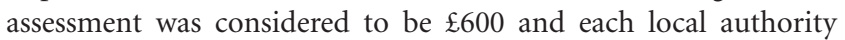
was given $\mathfrak{E} 600$ per assessment for their share of the assessments for the year 2009-2010. The changes are an important protection of the human rights of vulnerable people, but that protection comes at a cost. Often cost is ignored or brushed to one side as irrelevant to the policy questions involved; the implementation of DoLS, and the protections they provide, incurs a cost for the assessments themselves and which is an opportunity cost to health and social care services. If society is to ensure that the benefits of DoLS outweigh the costs then it is important to know what those costs are. Further, the cost in the first year as assessed by this study may underestimate the longer-term costs - there is potential for the first year's DoLS assessments to be just the tip of the iceberg. If it transpires that there are many more people who should be assessed then that may have significant budgetary implications. Additionally, there has been concern about the funding available for the implementation of DoLS and consultant psychiatrists have reported an increase in their workload after the implementation of the Mental Capacity Act 2005 without any compensatory increase in staffing levels. ${ }^{5-8}$ Therefore, a study to estimate the costs likely to be incurred with the implementation of the DoLS in England was undertaken. This study was approved by the ethics committees at the University of Central Lancashire and the University of Newcastle.

\section{Method}

\section{Resource utilisation for DoLS assessments}

Data on resource utilisation were ascertained from professionals conducting the six formal assessments for DoLS, the secretarial staff processing the DoLS assessments in local DoLS offices and the independent mental capacity advocates by a telephone interview using a specially designed brief questionnaire. The areas covered in the interview with the professionals conducting the six DoLS assessments were:

(a) grade and profession of the assessor for each of the six DoLS assessments;

(b) the average time required by professionals to conduct each of the six assessments for DoLS;

(c) the average travelling time of professionals conducting the six assessments for DoLS;

(d) the average travelling distance of professionals conducting the six assessments for DoLS;

(e) the number of people assessed by each interviewed professional for each of the six DoLS assessments;

(f) the percentage of people requiring referral to the Court of Protection and an independent mental capacity advocate.

The areas covered in the interview with the independent mental capacity advocates were essentially similar to those listed above except that they were not asked about the percentage of individuals who were referred to an independent mental capacity advocate. The areas covered in the interview with the secretarial staff in the DoLS office were: the average time required by secretarial staff to process the DoLS assessment and the number of people for whom they had processed DoLS assessments.

A total of 40 interviews including professionals conducting the six DoLS assessments, the secretarial staff in DoLS offices and the independent mental capacity advocates were planned. As it was likely that the range of professionals undertaking DoLS assessments would vary depending on the geographical location, and whether the supervisory body was the local authority or the primary care trust, four primary care trusts/local authorities representing the likely diversity of environments (rural/urban and north/south of England) were purposefully sampled from a Department of Health list. The administrators of the identified DoLS offices were contacted to obtain details of professionals undertaking the six DoLS assessments and the secretarial staff processing the DoLS assessments. The independent mental capacity advocates in the same geographical areas were identified from a list available from the Department of Health. ${ }^{9}$ As no interviews were secured from one DoLS office (although independent mental capacity advocate interviews were secured in that geographical area) and the numbers from the other three DoLS offices were comparatively small, two other DoLS offices were approached. Thus, six DoLS offices were approached in total. Three were in the north of England (two in the west (one rural and one urban) and one in the east (urban)), one in the midlands (urban), and two in the south (one in London and one on the south coast (rural)). Of the six DoLS offices, five were combined offices for primary care trusts and the local authority and one was a primary care trust office only.

\section{Time required for DoLS assessments}

A clear pattern emerged in all the DoLS offices for the assessment by the professional groups. All assessments were generally conducted by two different professionals: the professional conducting the mental health assessment and the professional conducting the best interests assessment. The reason these assessments segregated into those conducted by mental health and best interest assessors is that the mental health and best interests assessment cannot be conducted by the same person under the legislation for DoLS. Across the different DoLS offices the mental health assessor conducted anywhere between one and three (the mental health assessment and either mental capacity and/or eligibility assessments) of the six different DoLS assessments and the best interests assessor conducted anywhere between three and five (the ones the mental health assessor did not do) of the six different DoLS assessments; however, within each DoLS office the number and type of assessments for DoLS undertaken by the mental health and best interests assessors remained constant.

The heterogeneity in the assessment mix completed by mental health and best interest assessors was likely to drive variation in the overall costs of DoLS across regions. Qualification level and hence hourly costs of the assessors also varied across regions. Costs associated with travelling were likely to be higher in rural areas and may have been influenced by the availability of suitably qualified local assessors. The optimal approach where unit costs vary is to combine centre-specific resource use and unit costs to generate centre-specific overall costs. ${ }^{10}$ This was the approach taken in this study.

\section{Referrals to an independent mental capacity advocate and the Court of Protection}

Each of the professionals interviewed provided data on the total number of people they had assessed and the percentage of people who were referred to an independent mental capacity advocate. This allowed calculation of the weighted (for the number of people assessed by an individual professional) average percentage of people referred to the independent mental capacity advocates service. Data from professionals in all five regions were combined 
and applied to each DoLS office on the assumption that the proportion of people referred to an independent mental capacity advocate would not vary significantly by region. Each of the professionals and independent mental capacity advocates interviewed provided data on the total number of people they had assessed and the proportion of people who were referred to the Court of Protection. This allowed calculation of the weighted (for the number of people assessed by an individual professional or independent mental capacity advocate) average percentage of people referred to the Court of Protection in an analogous manner to the estimation of referrals to the independent mental capacity advocates service above. Data from all five regions were combined and applied to each DoLS office on the assumption that the proportion of people referred to the Court of Protection would not vary significantly by region.

\section{Unit costs for professionals, secretaries and the independent mental capacity advocates}

The average hourly unit costs, including add-on costs, for the different professionals with different grades involved in the six DoLS assessments were ascertained from the Unit Costs of Health and Social Services 2009. ${ }^{11}$

The average hourly unit costs, including add-on costs, for secretarial staff were estimated from data on local government salaries by region as provided in the Annual Survey of Hours and Earnings by the Office for National Statistics ${ }^{12}$ combined with add-on costs provided from the Unit Costs of Health and Social Care 2009. ${ }^{11}$

Most independent mental capacity advocates reported their profession as independent mental capacity advocate and were unable to supply a grade. Consequently, the unit $\operatorname{costs}^{11}$ for an adult social worker or social worker team leader (where indicated) were applied. Data for the independent mental capacity advocates service were not available from one area. These costs were estimated by recalculating the total costs for each independent mental capacity advocate interviewed after applying the unit cost relevant for the geographic status of the region with missing data. The average cost weighted by the number of cases dealt with by the independent mental capacity advocate was then estimated. Adjustments for London-based staff or staff based outside London were applied as appropriate. All costs were in 2008 British pounds.

\section{Travelling costs}

The cost of travelling was ascertained from local government figures for $2008 .{ }^{13}$ This was at a rate of $\mathfrak{£} 0.56$ per mile travelled.

\section{Cost of DoLS assessments conducted by professionals}

Each professional provided the average time taken for an individual DoLS assessment or for combined DoLS assessments when more than one of the six DoLS assessments were conducted together and the total number of people they had assessed since they undertook such work. Average travelling time and distance was also provided. Total assessment time for each individual (including travelling time) was multiplied by the unit cost for that professional, and a travelling allowance for mileage added. An average cost for mental health assessors in each DoLS office was estimated by taking a weighted average (for the number of people an individual professional had assessed) of the total cost estimated for an assessment by each mental health assessor in that DoLS office. The same procedure was applied to the interview data from best interest assessors in each DoLS office.

\section{Cost of secretarial time}

The same approach was used to estimate the weighted average secretarial staff time for each DoLS office. The weighted time for the secretaries processing the DoLS assessment and the unit cost of their salary allowed calculation of the total costs for secretarial time in processing a single DoLS assessment in each DoLS office.

\section{Cost of independent mental capacity advocates}

The same approach was used to estimate the weighted average time for independent mental capacity advocates in each DoLS office region. The total time, including travelling time, was combined with the appropriate unit cost for each independent mental capacity advocate interviewed. An allowance for mileage was added to generate an estimate of the total cost of independent mental capacity advocates. A weighted average for each DoLS office area (weighted on the number of reported cases undertaken) was taken. However, only a proportion of all cases assessed for DoLS are referred to the independent mental capacity advocates. The weighted percentage of cases assessed for DoLS referred to the independent mental capacity advocates was used to apportion the cost across all people assessed for DoLS (in other words a fraction of the total costs of the independent mental capacity advocates were apportioned across all people requiring DoLS assessment irrespective of referral to the independent mental capacity advocate).

\section{Cost of Court of Protection}

The 'Bournewood' consultation document ${ }^{14}$ and the regulatory impact assessment reported $£ 2050$ as the cost per case referred to the Court of Protection. This estimate was inflated for 2008 (£2262). Only a small percentage of all cases assessed for DoLS are referred to the Court of Protection. The weighted percentage of cases assessed for DoLS and referred to the Court of Protection was used to apportion the cost across all people assessed for DoLS (in other words a fraction of the total costs of the Court of Protection were apportioned across all people needing DoLS assessment irrespective of referral to Court of Protection).

\section{Managerial costs}

It was evident that most DoLS office managers fulfilled other duties alongside managing the DoLS office and many also undertook DoLS assessments themselves in the role of best interest assessor. The manager of each of the DoLS offices was contacted and the proportion of their time spent managing the DoLS assessment process was requested. Only one manager provided a specific estimate of the number of hours per week spent on managerial duties. Thus, the managerial costs are not further described.

\section{Costs of a single DoLS assessment}

The costs incurred as a result of the following activities were added together to give the total costs for a single assessment of DoLS in each DoLS office:

(a) cost of professionals (including travelling time and distance) in conducting the six DoLS assessments;

(b) cost of secretarial time for processing DoLS;

(c) cost of independent mental capacity advocates (including travelling time and distance) in conducting their assessments and apportioned across all those assessed;

(d) cost of Court of Protection apportioned across all those assessed. 
The average of the estimated cost for the assessment DoLS per person for each DoLS office was then calculated as the best estimate of the cost of DoLS assessment per person.

\section{Sensitivity analysis}

The average time taken by the best interest assessor was particularly high in one area (DoLS office 4). This was based on one interview, albeit with an assessor who was working full time and with considerable experience. Nevertheless, a sensitivity analysis with this observation removed to examine its impact on the overall estimate of the cost of a DoLS assessment was undertaken. This high observation was replaced with a weighted mean from the best interest assessor observations in the remaining four regions. A weighted average cost for assessment by the best interest assessor was determined from the assessment time recorded for all best interest assessors except the outlying observation. Unit costs were applied to the time appropriate to the grade of each best interest assessor assuming the same London/non-London status as the deleted observation. Travel costs were estimated separately. The weighted average travel time and travel distance from the mental health assessors in the region of interest were applied. Travel time was multiplied by the weighted average unit cost for best interest assessors assuming the same London/non-London status as the deleted observation. The resulting sum of assessment and travel costs was used in place of the outlying data from the best interest assessor and the mean cost across the five centres recalculated.

\section{Results}

A total of 37 professionals $(n=25)$ and secretaries $(n=6)$ in the DoLS offices and independent mental capacity advocates $(n=6)$ were interviewed. Collectively, these three groups had been involved in the DoLS assessment of 527 people, although some individuals may have been counted more than once as all three groups may have been involved with them.

One DoLS office provided no data on professional or secretarial involvement but did provide data from two independent mental capacity advocates. No cost was estimated for DoLS assessments from this office. The data from the two independent mental capacity advocates were used in combination with data from independent mental capacity advocates at four of the five other DoLS offices to estimate a weighted average cost of independent mental capacity advocates input in a DoLS assessment.

Table 1 shows the professional groups and grades undertaking each of the six DoLS assessments. Collectively, the interviewed professionals had conducted a total of 1161 of the individual DoLS assessments.

\section{Referrals to an independent mental capacity advocate and the court of Protection}

In total, $25 \%$ and $1.7 \%$ of people assessed for DoLS were estimated to require referral to an independent mental capacity advocate and the Court of Protection respectively.

\section{Cost of a single DoLS assessment}

Table 2 illustrates the total cost of a single assessment of DoLS in each of the DoLS offices. From DoLS office 2 there was no resource utilisation data from the independent mental capacity advocates and so the cost for independent mental capacity advocates was estimated for that office using methods described earlier.

The average cost for a single DoLS assessment across the five DoLS offices was $\mathfrak{E} 1277$. As there was a wide range in the cost of a single assessment for DoLS across the five DoLS offices, the standard deviation and 95\% confidence intervals around these costs were calculated on the assumption that these costs were normally distributed and that non-probabilistic sampling can be modelled as if it were a random sample. The standard deviation around the estimated cost of a single DoLS assessment was $\mathfrak{E 3 9 3}$ and the $95 \%$ confidence interval was $£ 506$ to $£ 2048$.

\section{Sensitivity analysis}

Costs in DoLS office 4 were particularly high, driven by the high costs of the best interest assessor inputs in this centre. The best interest assessor at this office conducted four of the six assessments and it was not clear why assessment times and consequently costs were higher in this centre. A sensitivity analysis was undertaken in which the cost of the best interest assessor input in this DoLS office was replaced with an imputed value based on assessment times from the remaining four DoLS offices and travel times for the Mental Health assessors from this office. The estimate of the costs of the best interest assessor input for DoLS office 4 (£935) was replaced with an imputed value of (£449). Overall costs for a DoLS assessment for office 4 fell from $\mathfrak{1 8 2 7}$ to $\mathfrak{E} 1341$. This reduced the overall mean across the five centres to $\mathfrak{E} 1180$, just under $\mathfrak{E} 100$ less than the original estimate.

\section{Post hoc analysis}

The Care Quality Commission recently reported that there have been 5200 DoLS assessments in the 9-month period from 1st April 2009 to December 2009. ${ }^{15}$ Based on these figures, assuming that there will be an even spread of DoLS assessments over the first year, it can be estimated that 6933 DoLS assessments will occur in the first year after the implementation of DoLS. Using the cost of a single DoLS assessment estimated in the current study (£1277), the total cost for these 6933 DoLS assessment was estimated at $£ 9000000$.

Table 1 Professional groups undertaking Deprivation of Liberty Safeguards assessments

\begin{tabular}{|c|c|c|c|c|c|c|c|c|}
\hline \multirow[b]{2}{*}{ Professional group } & \multirow[b]{2}{*}{$\begin{array}{c}\text { Professionals } \\
n\end{array}$} & \multirow[b]{2}{*}{$\begin{array}{l}\text { Individuals } \\
\text { assessed, } n\end{array}$} & \multicolumn{6}{|c|}{ Assessment, $n$} \\
\hline & & & $\begin{array}{c}\text { Mental } \\
\text { health }\end{array}$ & Age & $\begin{array}{c}\text { Mental } \\
\text { capacity }\end{array}$ & $\begin{array}{c}\text { Best } \\
\text { interest }\end{array}$ & Eligibility & No refusa \\
\hline Consultant psychiatrists & 6 & 77 & 77 & 0 & 65 & 0 & 65 & 0 \\
\hline Associate specialist in psychiatry & 2 & 9 & 9 & 0 & 1 & 0 & 8 & 0 \\
\hline Specialist registrar in psychiatry & 2 & 3 & 3 & 0 & 2 & 0 & 3 & 2 \\
\hline Specialty trainee year 6 doctor in psychiatry & 1 & 1 & 1 & 0 & 0 & 0 & 1 & 0 \\
\hline Senior social worker & 6 & 64 & 0 & 64 & 64 & 64 & 37 & 64 \\
\hline Social worker & 5 & 83 & 0 & 83 & 64 & 83 & 0 & 83 \\
\hline Community nurse & 2 & 8 & 0 & 7 & 8 & 7 & 7 & 7 \\
\hline Mental health nurse & 1 & 3 & 0 & 3 & 0 & 3 & 0 & 3 \\
\hline
\end{tabular}




\begin{tabular}{|c|c|c|c|c|c|}
\hline & \multicolumn{5}{|c|}{ f } \\
\hline & $\begin{array}{c}\text { DoLS } \\
\text { office } 1\end{array}$ & $\begin{array}{c}\text { DoLS } \\
\text { office } 2\end{array}$ & $\begin{array}{c}\text { DoLS } \\
\text { office } 3\end{array}$ & $\begin{array}{c}\text { DoLS } \\
\text { office } 4\end{array}$ & $\begin{array}{c}\text { DoLS } \\
\text { office } 5\end{array}$ \\
\hline Assessments by mental health assessor (including travelling time and distance) & 455 & 207 & 530 & 263 & 226 \\
\hline Assessments by best interests assessor (including travelling time and distance) & 639 & 384 & 269 & 935 & 521 \\
\hline Secretarial costs & 298 & 167 & 118 & 537 & 282 \\
\hline $\begin{array}{l}\text { Independent mental capacity advocates assessments } \\
\text { (including travelling time and distance) apportioned to each person assessed }\end{array}$ & 103 & 79 & 56 & 54 & 67 \\
\hline Court of Protection costs apportioned to each person assessed & 39 & 39 & 39 & 39 & 39 \\
\hline Total & 1534 & 877 & 1013 & 1827 & 1134 \\
\hline
\end{tabular}

\section{Discussion}

\section{Limitations}

The costs associated with the time of professionals in the managing authority and relatives and carers where they were interviewed or consulted by the professionals conducting the six assessments for DoLS and independent mental capacity advocates were not included because it was not possible to accurately estimate this. The relevant person's representative, who is likely to be someone close to the assessed individual authorised under DoLS, is likely to incur costs related to the actual use of their time in discharging their responsibilities, travelling, loss of earnings and loss of leisure time, but these were not estimated because the main focus of this study was to determine the budgetary impact of DoLS legislation on health and social services budgets. Also, a small number of these representatives are formally paid, but this was not included as the numbers for this are unknown and likely to be small. Although the cost of professionals conducting the six DoLS assessments and the independent mental capacity advocates were included, any additional time commitments after the assessment was completed were not included. For example, the time required by the professional conducting the DoLS assessments to inform staff in the managing authority, the assessed individual, relatives and carers of the outcome of the assessment. The cost of Mental Health Act 1983 assessments that may be required after completion of the DoLS assessments when the eligibility assessment recommends a Mental Health Act assessment were not included because the number of such assessments was unknown. However, the DoLS assessment process may lead to an increase in Mental Health Act assessments because DoLS is contingent on refusal, and there is recent evidence of an increase in the number of detentions under the Mental Health Act 1983. The cost of reassessment for authorisation when the original authorisation lapsed was also not estimated because accurate data on the duration of authorisation were not available. The management costs of a single DoLS assessment were not included because data on this were only available from one DoLS office. All the costs were for the year 2008 as the latest available data on salary costs and other costs were for 2008. The concerns listed thus far are likely to result in an underestimate of the true cost in the current study. This underestimate could be reduced to produce a figure closer to the correct one by estimating some of the missing data, and this was done where possible (for example missing independent mental capacity advocates data from one DoLS area), but was not always feasible.

Although this study used a bottom-up approach, a top-down approach could have been used, whereby the total national budget for DoLS could simply be divided by the total national number of DoLS assessments. However, the latter approach would not necessarily be more accurate for several reasons. The national figures for the number of DoLS assessments available thus far were only for the first 9 months and they may not have been accurate. The DoLS offices and the independent mental capacity advocates may be part of a department serving several other functions. For example, the best interests assessors for DoLS were also working as approved mental health professionals for the Mental Health Act 1983 and the managers of DoLS offices also conducted some of the DoLS assessments and other functions. Thus, in reality, professionals may be cross-subsidising costs through unpaid overtime or other budgets, or the DoLS budget may be subsidising other work. The bottom-up approach used circumvents these issues, whereas the top-down approach would not.

The legislation for DoLS and the accompanying Code of Practice do not provide formal guidance about the order in which the six different assessments for DoLS should be conducted. The order in which the different DoLS assessments are conducted may, therefore, vary across different DoLS offices; anecdotally, this was observed in the current study. It is possible that the remainder of the DoLS assessments would be abandoned if one of the assessments indicates that authorisation cannot be granted. For example, if the mental health assessment is the first assessment and the individual is found not to have a mental disorder, then the other five assessments are likely to be aborted. However, in the costing analysis it was assumed that every individual would receive all six assessments. This approach is likely to provide a higher estimate of the true cost. For one DoLS office no independent mental capacity advocates were interviewed and for that DoLS office a weighted average cost of the assessment of an independent mental capacity advocate from other DoLS offices was used; this may have biased the costing analysis. Also, an assumption that individuals requiring independent mental capacity advocates would be the same in rural and urban areas was made in the absence of any evidence to the contrary. However, this is unlikely to significantly affect the costs because the cost of independent mental capacity advocates made only a small contribution to the overall cost. Forty interviews were originally planned with professionals conducting the six DoLS assessments, the secretarial staff processing the DoLS assessments and the independent mental capacity advocates. However, only 37 interviews were secured. This discrepancy is unlikely to have affected the results. Moreover, the 37 respondents had experience of 527 people referred for assessment of DoLS and a total of 1161 individual assessments for DoLS. The studied DoLS offices were purposefully sampled rather than randomly selected. It is not possible to be certain that the range of professionals from all relevant disciplines and grades involved in the DoLS assessments were captured by the study design.

The variation in the cost of a single DoLS assessment observed across the different DoLS offices may be the result of the following factors. 
(a) The methodological difficulties discussed earlier.

(b) Professionals interviewed may not be representative of all professionals undertaking DoLS assessments.

(c) Data collected from professionals were not verified independently and may be subject to recall bias. This recall bias could lead to an under- or an overestimate of the costs and it was difficult to predict the direction of this bias. The bias could have been reduced by asking the professionals, secretaries and independent mental capacity advocates to keep a prospective time diary for a month but this was beyond the scope of this study.

(d) Differing definitions of deprivation of liberty used by different DoLS assessors. ${ }^{2,16}$

(e) Differing interpretations of the criteria for the six different DoLS assessments used by different professionals.

(f) Differing interpretation of the interface of DoLS and the Mental Health Act 1983.

(g) Differing geographical locations leading to variable travelling times and distances.

(h) Differing characteristics of individuals referred for DoLS assessments.

(i) Differing grades and professions of the DoLS assessors.

Costs for the best interest assessor input were notably higher in DoLS office 4 than in the other four offices. These data were based on a single interview. The assessor was working full time on best interest assessments and had conducted 56 assessments. It seems unlikely that the assessor was inexperienced in the role or that their recall of time taken for assessments would be particularly poor. Replacing this data with an imputed value based on assessment times in the other four offices reduces the overall estimate of the cost of a DoLS assessment by just under $£ 100$.

\section{Findings}

The government estimated that there would be 20000 assessments for DoLS in England at a cost of $\mathfrak{E 6 0 0}$ each and funded local authorities and the NHS in accordance with this. The average cost of a single DoLS assessment estimated in this study was significantly higher than the government's estimate of $\mathfrak{E} 600$. However, the government's figure of $\mathfrak{E} 600$ was within the $95 \%$ confidence interval for the estimated cost of a single DoLS assessment for the five DoLS offices, and was at the lower end of this $95 \%$ confidence interval. It is likely that the figure of $\mathfrak{E} 600$ would drop below the $95 \%$ confidence interval if:

(a) the estimated costs were corrected for costs for 2009/2010;

(b) managerial costs were included;

(c) costs of the best interests assessor in securing the person's representative for the individual assessed where the authorisation for DoLS is granted were included;

(d) costs of the DoLS assessors in liaising with the managing authority staff, people assessed for DoLS and family members after the assessment is completed were included.

The methodological issues discussed earlier may also be important in this context, although it is likely that correction of the methodological issues would increase the estimated costs further rather then reduce them. Moreover, the costs estimated in this study were based on data acquired from the actual experience and practice of the professionals conducting the six assessments for DoLS, secretarial staff in the DoLS office processing the request for DoLS assessments and the independent mental capacity advocates; these 37 respondents had experience of
527 people referred for a DoLS assessment and a total of 1161 separate DoLS assessments. Furthermore, these respondents were drawn from six separate DoLS offices from diverse urban/rural and north/south locations. Thus, the estimated cost for a single DoLS assessment determined in this study is likely to be closer

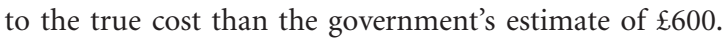

Estimating the cost for each type of staff group and for each assessment would identify areas that are more expensive and allow the development of more efficient service delivery models. However, the current study was not designed to examine this. Also, other factors like statutory requirements, local models of service delivery and availability of personnel may influence this.

It would have been interesting to estimate the cost of using the guardianship order instead of DoLS, for comparative purposes, because amendments to the guardianship order were seriously considered as an alternative to DoLS to comply with the European Court of Human Rights' judgment on the Bournewood case. However, in the absence of the precise criteria for the 'amended' guardianship order and in the absence of resource utilisation data for guardianship orders used in this context, it was not possible to estimate these costs.

\section{Implications}

If the estimated cost in this study is closer to the true cost and if the government's estimate of the number of DoLS assessments in the first year of 20000 were actually conducted, then there would be a shortfall in the allocated budget for DoLS on the basis of a cost of $£ 600$ for a single assessment. The Care Quality Commission has recently reported that in the first 9 months until December 2009 since the implementation of DoLS in April 2009, there have only been 5200 DoLS assessments. ${ }^{15}$ Unless there is a surge in assessments in the remaining 3 months of the first year, the allocated budgets will turn out to be satisfactory because the number of assessments would have been lower than predicted, but not the actual cost of the single assessment.

The reasons for the discrepancy between the government's estimate and the actual number of people reported to have had an assessment for DoLS include the following. There is a possibility that not all individuals assessed for DoLS by individual DoLS offices have been reported centrally. Also, some people referred for a DoLS assessment may not have been assessed by the supervisory bodies. In addition, deprivation of liberty is not clearly defined in the legislation and the accompanying Code of Practice and this may have led to variable interpretation of the definition of deprivation of liberty and variable application of the potential criteria for deprivation of liberty from case law in the managing authorities. ${ }^{2,16}$ A Welsh study of hospitals failed to identify a single case of deprivation of liberty. ${ }^{17}$ The authors argued that this may be because it may be very difficult to meet the threshold for deprivation of liberty ${ }^{17}$ given that it is not defined in the legislation and is based on case law.

Another possible reason for the discrepancy is that clinicians have expressed concern about the discrimination between restriction and deprivation of liberty. ${ }^{2,5-7}$ The former does not require DoLS and the latter does. Also, the code of practice for DoLS recommends that measures should be taken to remove deprivation of liberty before referral for an assessment for DoLS. It is possible that this may have been an effective recommendation to reduce the number of people deprived of liberty. It is also possible that there may be reduced awareness of the legislation for DoLS in the managing authorities and, therefore, it is used less often; reduced awareness may lead to the legislation not being applied appropriately and, in turn, lead to variations in different settings and regions. This has been observed previously with the 
use of the guardianship order in the Mental Health Act 1983. Finally, the eligibility assessment for DoLS can lead to a recommendation for assessment under the Mental Health Act 1983. It is possible that the managing authorities are using the Mental Health Act rather than DoLS in anticipation that the referred individual may fail the eligibility test for DoLS. This would largely only account for the lower numbers receiving DoLS assessments in mental health hospital settings and would not overtly influence the other two settings (where the Mental Health Act 1983 is traditionally not used), although there may also have been an increase in the use of community treatment orders and guardianship orders with the condition of staying in the nursing or residential home.

Our interpretation of the findings suggest that future research needs to identify the range and variability in the definitions of deprivation of liberty used by the staff in managing authorities and the DoLS assessors from supervisory bodies. We also need to identify the range and variability in the interpretation of the criteria used in the five assessments for DoLS (other than the age assessment). At present the DoLS legislation and the accompanying Code of Practice do not stipulate or recommend the order in which the six different DoLS assessments should be conducted. Anecdotally, the order in which the DoLS assessments are carried out seems to vary across the different DoLS offices and it would be helpful to have clear recommendations on this. Thus, if an assessment is failed then the remaining assessments are not conducted and the individuals spared further assessments and the cost of additional assessments is saved. Some local DoLS offices appear to have developed protocols for this and it may be helpful to have these centralised. In addition, further research is needed to continue to collect data on activity (the number of referrals for DoLS, the assessment time, the travelling time, the travelling distance, the grade and discipline of the professionals, managers, secretaries and independent mental capacity advocates involved in the assessments), and the outcome of each of the six assessments and the reasons for this. This would allow a better understanding of the process and content of the DoLS assessments and enable a more accurate estimate of the costs. The latter would be of importance to policy-makers and both the managing authorities and supervisory bodies.

Ajit Shah, MBChB, FRCPsych, School of Health, University of Central Lancashire, Preston; Mark Pennington, BSC, MSC, PhD, Institute of Health and Society, University of Newcastle, Newcastle; Chris Heginbotham, OBE, MSC, MA, MPhil, School of Health, University of Central Lancashire, Preston; Cam Donaldson, PhD, Yunus Centre for Social Business and Health, Glasgow Caledonian University, Glasgow, UK.

Correspondence: Ajit Shah, West London Mental Health NHS Trust, Uxbridge Road, Southall, Middlesex UB1 3EU, UK. Email: ajitshah123@btinternet.com

First received 14 Nov 2010, final revision 2 Mar 2011, accepted 21 Mar 2011

\section{Funding}

The Nuffield Foundation funded this project.

\section{Acknowledgements}

We are grateful to all the managers, administrators, DoLS assessors, independent mental capacity advocates and secretaries for participating in this study. We are also grateful to the three anonymous reviewers for their helpful comments.

\section{References}

1 HL V UK. European Court of Human Rights (application no. 45508/99). Judgment, Strasbourg, 5 October 2004.

2 Shah AK, Heginbotham C. Newly introduced deprivation of liberty safeguards: anomalies and concerns. Psychiatrist 2010; 34: 243-5.

3 Ministry of Justice and Department of Health. Impact Assessment of the Mental Capacity Act 2005 Deprivation of Liberty Safeguards to accompany the Code of Practice and Regulations. Department of Health, 2008 (http:// www.dh.gov.uk/prod_consum_dh/groups/dh_digitalassets/documents/ digitalasset/dh_084984.pdf)

4 Department of Health. Mental Capacity Act 2005 Deprivation of Liberty Safeguards Implimentation/Commissioning Q\&A. Department of Health, 2009 (http://www.dh.gov.uk/prod_consum_dh/groups/dh_digitalassets/ documents/digitalasset/dh_094793.pdf).

5 Shah AK, Banner, N, Heginbotham C, Fulford B. The early experience of old age psychiatrists in the application of the Mental Capacity Act 2005: a pilot study. Int Psychogeriatr 2010; 22: 147-57.

6 Shah AK, Banner N, Heginbotham C, Fulford W. A pilot study of the early implementation of the Mental Capacity act 2005 in England and Wales: the experience of consultants in Old Age Psychiatry. Med Sci Law 2010; 50: 1315 .

7 Shah AK, Banner N, Heginbotham C, Fulford B. The application of the Mental Capacity Act 2005 among geriatric psychiatry patients: a pilot study. Int Psychogeriatr 2009; 21: 922-30.

8 Shah A, Heginbotham C, Fulford W, Banner N, Newbiggin K, Kinton M. A pilot study of early experience of consultant psychiatrists in the implementation of the Mental Capacity Act 2005: local policy and training, assessment of capacity and determination of best interests. J Ment Health Law 2009; Winter: 149-64.

9 Department of Health. IMCA Organisations Apppointed: As at 16th October 2009. Department of Health, 2009 (http://www.dh.gov.uk/ prod_consum_dh/groups/dh_digitalassets/@dh/@en/@pg/documents/ digitalasset/dh_107198.pdf).

10 Raikou M, Briggs A, Gray A, McGuire A. Centre-specific or average unit costs in multi-centre studies? Some theory and simulation. Health Econ 2000; 9: 191-8.

11 Curtis L. Unit Costs of Health and Social Care 2009. Personal Social Services Research Unit, University of Kent, 2009.

12 Office for National Statistics. Annual Survey of Hours and Earnings (ASHE) - 2003 Results. Office for National Statistics, 2009 (http:// www.statistics.gov.uk/statbase/Product.asp?vInk=13107\&More).

13 National Association for Voluntary and Community Action. Local Authority Mileage Rates 2007/08. NAVCA, 2007 (http://www.voscur.org/system/files/ 16mileage.pdf).

14 Department of Health. "Bournewood" Consultation. The Approach to be taken in Response to Judgment of the European Court of Human Rights in the "Bournewood" Case. Department of Health, 2005 (http:// webarchive.nationalarchives.gov.uk/+/www.dh.gov.uk/en/Consultations/ Closedconsultations/DH_4113613).

15 Care Quality Commission. Annex B: Deprivation of Liberty Safeguards. CQC, 2010 (http://www.cqc.org.uk/_db/_documents/20100211_CM100105_ Annex_B_Deprivation_of_liberty_safeguards.doc).

16 Cairns R, Richardson G, Hotopf M. Deprivation of liberty: Mental Capacity Act safeguards versus Mental Health Act. Psychiatrist 2010; 34: 246-7.

17 Lepping P, Sambhi RH, William-Jones K. Deprivation of Liberty Safeguards: how prepared are we? J Med Ethics 2010; 36: 170-3. 